\title{
Vasomotor and Other Menopausal Symptoms Influenced by Menopausal Stage and Psychosocial Factors in Japanese Middle-Aged Women
}

\author{
Kuninori Shiwaku', Yosuke Yamane ${ }^{1}$, Iwao Sugimura ${ }^{2}$, Masato Hayashi $^{3}$, \\ Masami NoJiri $^{4}$, Shosui Matsushima ${ }^{5}$ and Wasaku Koyama ${ }^{6}$ \\ ${ }^{1}$ Department of Environmental Medicine, Shimane Medical University, ${ }^{2}$ Asahikawa Kosei Hospital, \\ ${ }^{3}$ Hiraga General Hospital, ${ }^{4}$ School of Nursing, Chiba University, ${ }^{5}$ Saku General Hospital and \\ ${ }^{6}$ Kumamoto Health Care Center, Japanese Red Cross
}

\begin{abstract}
Vasomotor and Other Menopausal Symptoms Influenced by Menopausal Stage and Psychosocial Factors in Japanese Middle-Aged Women: Kuninori Shiwaku, et al. Department of Environmental Medicine, Shimane Medical University-The relationship among menopausal symptoms, the menopausal stage and psychosocial factors in climacteric of Japanese women was investigated. Information on menopausal symptoms, the menstrual cycle and psychosocial factors were collected by means of a self-reported questionnaire in six rural communities. A general population sample of 2,886 women (recovery rate of $75 \%$ ) aged 40 to $69 \mathrm{yr}$ completed a report on seventeen self-reported health symptoms over the preceding 12 months. The most bothersome complaints were aching/painful joints, weakness and headache that were reported by approximately half the population aged 40 to $69 \mathrm{yr}$, but less than $4 \%$ of the women were affected severely. One-third of the women were bothered by night sweats, cold hands and feet, nervousness and anxiety. Approximately one in five of the women complained of hot flushes, numbness, early waking, and sleeplessness. Four factors emerged from a factor analysis: general somatic symptoms, psychological symptoms, vasomotor symptoms and aging symptoms. Hot flushes, night sweats, numbness, early waking and sleeplessness were significantly higher in the perimenopausal and postmenopausal periods than in the premenopausal period of women aged 45 to $54 \mathrm{yr}$. The menopausal stages were significantly related to the vasomotor symptoms, but had little relationship to the other menopausal symptoms, in a logistic
\end{abstract}

Received May 11, 2001; Accepted Sep 6, 2001

Correspondence to: K. Shiwaku, Department of Environmental Medicine, Shimane Medical University, Izumo City, Shimane 6938501, Japan regression model. Japanese women characteristically have a lower incidence of vasomotor and other menopausal symptoms, and a lower utilization of medical treatment for menopausal symptoms. Vasomotor symptoms were clearly associated with menopause, but other menopausal symptoms in Japanese middle-aged women related to self-rated health, social support and occupation.

(J Occup Health 2001; 43: 356-364)

Key words: Menopausal symptoms, Psychosocial factors, Japanese women

The mid-life period is regarded as a time of profound physical and psychosocial change for working women. The most obvious evidence of aging in middle-aged women is cessation of menstruation, which clearly marks the transition from the reproductive phase of life to senescence. The climacteric begins several yr before menopause with symptoms, and terminates when ovarian function ceases. Women complain of hot flushes and night sweats, both known as vasomotor complaints, vaginal dryness and various but characteristic psychological symptoms in the perimenopausal period ${ }^{1 \cdot 2 !}$. Recent studies in Europe and North America have confirmed that vasomotor symptoms increase during the menopausal transition. Although other symptoms did not increase when women became postmenopausal, some of the prospective studies have shown an increase in general symptoms reported during perimenopause ${ }^{3,4}$.

Alternatively, it is argued that women's health and well being in midlife are more attributable to their social circumstances, in particular life stress associated with changing social roles ${ }^{3}$. Cross-cultural research also provides evidence of women having positive attitudes about menopause and few or no symptoms ${ }^{3,5-8)}$. Frequency of 
Table 1. Demographic data on Japanese women in six rural communities

\begin{tabular}{|c|c|c|c|c|c|}
\hline & Daiyu & Nishiizu & Usuda & Izumo & Toyono \\
\hline Category of rural community & Plain & Fishery-rural & Mountainous & Plain & Plain \\
\hline \multicolumn{6}{|l|}{ 40-69 yr old } \\
\hline Sample & 584 & 662 & 1,862 & 520 & 200 \\
\hline Response & 575 & 598 & 1,114 & 451 & 148 \\
\hline Age & $57.1 \pm 8.5$ & $57.9 \pm 8.1$ & $57.0 \pm 8.3$ & $57.8 \pm 7.2$ & $55.5 \pm 8.4$ \\
\hline Number in family & $4.8 \pm 1.8$ & $3.1 \pm 1.6$ & $3.6 \pm 1.7$ & $4.2 \pm 2.0$ & $4.5 \pm 2.0$ \\
\hline Farmer & $207 / 574(36.1 \%)$ & $64 / 598(10.7 \%)$ & $232 / 1111(20.9 \%)$ & $131 / 407(32.2 \%)$ & $53 / 119(44.5 \%)$ \\
\hline Caring of elderly & $65 / 563(11.5 \%)$ & $63 / 555(11.4 \%)$ & $200 / 1105(18.1 \%)$ & $49 / 443(11.1 \%)$ & $19 / 144(13.2 \%)$ \\
\hline Smoking & $53 / 574(9.2 \%)$ & $47 / 532(8.8 \%)$ & $51 / 1114(4.6 \%)$ & $19 / 435(4.4 \%)$ & $3 / 147(2.0 \%)$ \\
\hline Treatment by gynaecologist & $9 / 510(1.8 \%)$ & - & $27 / 1114(2.4 \%)$ & $8 / 450(1.8 \%)$ & $8 / 147(5.4 \%)$ \\
\hline \multicolumn{6}{|l|}{$45-54$ yr old } \\
\hline Response & 156 & 170 & 295 & 113 & 39 \\
\hline Age & $49.2 \pm 3.0$ & $49.5 \pm 2.9$ & $50.0 \pm 3.3$ & $50.1 \pm 3.0$ & $49.3 \pm 3.6$ \\
\hline Number in family & $4.4 \pm 1.6$ & $3.5 \pm 1.4$ & $3.9 \pm 1.5$ & $4.0 \pm 1.5$ & $4.2 \pm 1.4$ \\
\hline Farmer & $54 / 156(34.6 \%)$ & $4 / 170(2.4 \%)$ & $30 / 295(10.2 \%)$ & $25 / 107(23.4 \%)$ & $11 / 35(31.4 \%)$ \\
\hline Caring of elderly & $18 / 152(11.8 \%)$ & $20 / 162(12.3 \%)$ & $51 / 293(17.4 \%)$ & $9 / 111(8.1 \%)$ & $4 / 38(10.5 \%)$ \\
\hline Smoking & $10 / 155(6.5 \%)$ & $14 / 160(8.8 \%)$ & $21 / 295(7.1 \%)$ & $6 / 109(5.5 \%)$ & $1 / 39(2.6 \%)$ \\
\hline Treatment by gynaecologist & $5 / 140(3.6 \%)$ & - & $21 / 295(7.1 \%)$ & $4 / 113(3.5 \%)$ & $3 / 39(7.7 \%)$ \\
\hline
\end{tabular}

Treatment of menopausal symptoms was not surveyed in Nishiizu.

symptoms reported in Japan among a nonclinical, naturally menopausal population was remarkable lower and different from that in North American women ${ }^{83}$. Lock (1991) suggested that the psychological impact of menopause was influenced by social values as well as cultural differences affecting lifestyle factors ${ }^{7,8}$. Hormone replacement therapy (HRT) has been popular in the USA ${ }^{9)}$ and Europe ${ }^{(0)}$, but used by only a few in Japan ${ }^{8.11}$. Cultural and psychosocial factors of their respective societies may influence women in the climacteric and the use of HRT to ease severe menopausal symptoms, but there are few data on menopausal symptoms in $\operatorname{Japan}^{7,8,11 !}$.

We conducted a cross-sectional survey of Japanese women to assess the relationships among menopausal symptoms, the menopausal stage and psychosocial factors such as self-rated health ${ }^{12)}$, life satisfaction ${ }^{137}$ and social support ${ }^{14)}$ in the menopausal transition.

\section{Methods}

We analysed the cross-sectional survey data from the Study of Health Promotion for Japanese Women. Keeping in mind the cultural differences in Japan, we invited all women $(n=3,826)$ aged 40 to 69 from civil registry based lists of six rural communities in various parts of Japan (Daiyu in Akita, Usuda in Nagano, Nishiizu in Shizuoka, Izumo in Shimane and Toyono in Kumamoto) to participate in the present study; we also provided them with information about the purpose of the study. We utilized a self-reported questionnaire containing questions on menopausal symptoms, menopausal stage, self-related health, life satisfaction, lifestyle and demographics. The questionnaire was distributed and collected through the community organizations in 1997 . The questionnaire was returned by 2,886 women $(57.3 \pm 8.2$ yr old $)$; the overall recovery rate for the communities was $75.4 \%$ (ranging from $60.0 \%$ to $98.5 \%$ ). Table 1 shows demographic data of the six communities. Daiyu, Izumo and Toyono are plain rural communities with rice and other commercial crops. Nishiizu is a fishery-rural community and famous resort area where residents engage in part-time work. Usuda is a mountainous community but the majority of residents work in the manufacturing and service industries.

For purposes of the present investigation, women were classified as postmenopausal on the basis of the reported last menstrual cycle if periods had ceased for more than 12 months, and were classified as perimenopausal if periods had ceased for between three and twelve months or were reported to be less regular. All other women were defined as premenopausal.

Menopausal symptoms were studied for one yr. Menopausal symptoms included hot flushes and night sweats, both known as vasomotor complaints, and 15 other common complaints: cold hands and feet, shortness of breath, numbness, paresthesia, early waking, sleeplessness, irritability, nervousness, anxiety, dizziness, weakness, aching/painful joints, headache, palpitations and formication ${ }^{15)}$, based on the Kupperman's menopausal inde ${ }^{1)}$. Information was collected regarding the specialty 
of doctors who treated women for these symptoms except for Nishiizu. No data on hormone profiles were gathered. as it would be of little value in predicting either the duration or the severity of climacteric symptoms ${ }^{16}$. The severity of complaints was indicated on a four-point scale and weighted as absent in 0 , slight in 1 , moderate in 2 and severe in 3 .

Self-rated health and life-satisfaction were ranged on a five-point scale from very poor to excellent. Lifestyle was measured with an 8-item questionnaire: eating breakfast, nutritional balance, sleeping for 7 or $8 \mathrm{~h}$, working for less than $9 \mathrm{~h}$, resting when tired, exercise for over 20 min twice a week, not smoking, and alcohol consumption below 20 $\mathrm{g}$ a day. Scores were calculated by totalling the number of positive answers to these 8 items. Social support consisted of two items: "Do you have persons with whom you feel relaxed? (Close friends)", and, "Do you contribute to your family and community? (Social role)". Occupation, caring of elderly in their home and the number in the family were surveyed as demographic data.

Statistical analysis was performed with SPSS (SPSS. Inc., Chicago, IL, USA) for all women aged 40 to $69 \mathrm{yr}$ $(n=2,886)$ and for the women aged 45 to $54 \mathrm{yr}(\mathrm{n}=773)$. Women aged 45 to $54 \mathrm{yr}$ were deemed to be in the climacteric period as $50.5 \mathrm{yr}$ is the average age of natural menopause ${ }^{17,18)}$; this range of ages was suitable for estimating the effects of menopause without the aging influence. Menopausal symptoms were analysed by integrating the positive complaints from slight to severe, because of the small proportions of moderate and severe. The factor analysis was undertaken of 17 menopausal symptoms for women by the principal components methods with a varimax rotation. Factor analysis was used to structure the investigations and to combine some of the symptoms with high factor loadings into a number of symptom groups. General $\chi^{2}$ test was used to compare community, self-rated health, life satisfaction, social support, lifestyle, occupation, and taking care of the elderly as a function of the menopausal status and symptoms. General $\chi^{2}$ test for three age groups or three menopausal symptom reporting groups and post hoc analysis by means of $\chi^{2}$ test for two independent samples were used for the frequency of each menopausal symptom. One-way ANOVA for three age groups or three menopausal symptom reporting groups were used for age, lifestyle score and the number of family. Logistic regression was used to test for differences between the menopausal symptom reporting groups adjusted for age, menopausal stages, selfrated health, life satisfaction, social support, occupation and behavioural variables. Unless otherwise noted, a nominal two-sided $P$ value less than 0.05 was used to assess significance. The critical alpha value of post hoc analysis with the $\chi^{2}$ test for two independent samples was adjusted with Bonferroni's inequality to take into account the potential for increasing Type I error ${ }^{19}$.

\section{Results}

Menopausal symptoms in women aged 40 to $69 \mathrm{yr}$

$8.9 \%$ of the women in their $40 \mathrm{~s}$ were postmenopausal, and $16.3 \%$ were perimenopausal; women in their 50 s were $79.5 \%$ postmenopausal and $13.1 \%$ perimenopausal; women in their $60 \mathrm{~s}$ were $100.0 \%$ postmenopausal (Table 2 ). The perimenopausal women's average age was 49.2 $\pm 3.9 \mathrm{yr}(34-58 \mathrm{yr})$. The most bothersome complaints were aching/painful joints, weakness and headaches, which were reported by approximately half the population, but less than $4 \%$ of the women were affected severely. A third of the women were bothered by night sweats, cold hands and feet, nervousness and anxiety. About one in five women complained of hot flushes, numbness, early waking and sleeplessness.

Frequency of hot flushes, night sweats and numbness was the highest in the postmenopausal 40 s group and in the perimenopausal $50 \mathrm{~s}$ group, and decreased in the $60 \mathrm{~s}$ women. Shortness of breath, anxiety, dizziness and palpitations increased in the perimenopausal $40 \mathrm{~s}$ and $50 \mathrm{~s}$ women, as compared to the premenopausal and postmenopausal groups of the same ages. These latter menopausal symptoms did not change with the postmenopausal stage. Treatment by gynaecologists was most frequent in the 40 s group, then decreased with age in spite of greater frequency of vasomotor and other menopausal symptoms (Table 2).

Self-rated health, life satisfaction and social environment

Self-rated health tended to become worse with age (Table 2). Premenopausal women felt healthier than those in both the perimenopausal and postmenopausal stages (data not shown). Life satisfaction increased slightly with age (Table 2) and decreased in perimenopausal women in comparison with the premenopausal and postmenopausal groups. Having close friends was rated equally in the three menopausal stages, but perimenopausal women felt that they made little contribution to their families and communities. Lifestyle improved with age and the 60 s women felt they had the best lifestyle (Table 2). The number in the family decreased with age (Table 2 ) and with less regularity of the menstrual cycle. Seventeen percent of the 50 s women took care of the elderly in the home, and the $50 \mathrm{~s}$ women and those with less menstrual cycle regularity cared for the elderly in higher proportion (Table 2).

\section{Menopausal symptoms of women aged 45 to $54 \mathrm{yr}$}

Hot flushes, night sweats, numbness, carly waking and sleeplessness were significantly higher in the perimenopausal and postmenopausal women than in the premenopausal group. Frequency of anxiety, weakness and palpitations increased in the perimenopausal stage, compared with the other menopausal stages (Fig. 1). A 
Table 2. Menopausal stage and psychosocial factors for women aged 40 to $69 \mathrm{yr}$ by age

\begin{tabular}{|c|c|c|c|c|}
\hline & $40-49 \mathrm{yr}$ & $50-59 \mathrm{yr}$ & $60-69$ yr & $P$ value \\
\hline Number & 648 & 865 & 1,373 & \\
\hline \multicolumn{5}{|l|}{ Menopausal stage } \\
\hline Premenopausal & $478 / 639(74.8 \%)$ & $60 / 849(7.1 \%)^{* * *}$ & $0 / 1373(0.0 \%)^{* * *}$ & $<0.001$ \\
\hline Perimenopausal & $104 / 639(16.3 \%)$ & $107 / 849(12.6 \%)^{* * *}$ & $0 / 1373(0.0 \%)^{* * *}$ & $<0.001$ \\
\hline Postmenopausal & $57 / 639(8.9 \%)$ & $682 / 849(80.3 \%)^{* * *}$ & $1373 / 1373(100.0 \%)^{* * * *}$ & $<0.001$ \\
\hline Treatment by gynecologist & $25 / 508(4.9 \%)$ & $20 / 678(2.9 \%)$ & $7 / 1034(0.7 \%)^{* * *}$ & $<0.001$ \\
\hline \multicolumn{5}{|l|}{ Health } \\
\hline Self-rated health (Excellent/good) & $170 / 646(26.3 \%)$ & $174 / 861(20.2 \%)^{*}$ & $253 / 1366(18.5 \%)^{* * *}$ & $<0.001$ \\
\hline Life-satisfaction (Excellent/good) & $151 / 642(23.5 \%)$ & $212 / 858(24.7 \%)$ & $358 / 1365(26.2 \%)$ & 0.400 \\
\hline \multicolumn{5}{|l|}{ Social support } \\
\hline Friends (Yes) & $452 / 635(71.2 \%)$ & $600 / 848(70.8 \%)$ & $919 / 1318(69.7 \%)$ & 0.770 \\
\hline Social role (Yes) & $297 / 632(47.0 \%)$ & $408 / 840(48.6 \%)$ & $636 / 1294(49.1 \%)$ & 0.672 \\
\hline Lifestyle score & $5.80 \pm 1.35$ & $6.04 \pm 1.38 * * *$ & $6.53 \pm 1.26^{* * *}$ & $<0.001$ \\
\hline Farmer & $85 / 642(13.2 \%)$ & $176 / 850(20.7 \%)^{* * *}$ & $426 / 1317(32.3 \%)^{* * *}$ & $<0.001$ \\
\hline Number in family & $4.59 \pm 1.56$ & $3.64 \pm 1.65 * * *$ & $3.68 \pm 2.01 * * *$ & $<0.001$ \\
\hline Caring of elderly & $69 / 635(10.9 \%)$ & $147 / 849(17.3 \%)^{* * *}$ & $180 / 1326(13.6 \%)$ & $<0.001$ \\
\hline
\end{tabular}

$P$ values of the two comparisons by using $\chi^{2}$ test were expressed as *: $P<0.025$, **; $P<0.005$ and ***; $P<0.0005$, compared with women aged $40-49$, after general $\chi^{2}$ test for the three independent samples. $P$ values of the two comparisons by using Scheffe's method were expressed as **: $P<0.01$ and $* * *: P<0.001$, compared with women aged 40-49, after one-way ANOVA for the three independent samples.

fifth of the women aged 45-54 yr were treated by medical doctors for these menopausal symptoms, but only $4.6 \%$ visited a gynaecologist and $1.5 \%$ consulted a psychiatrist or neurologist. Perimenopausal women were more than twice as likely to consult a gynaecologist than were the premenopausal and postmenopausal groups (data not shown).

A factor analysis was used to group the 17 menopausal symptoms into meaningful categories (Table 3). Four factors emerged from a factor analysis of these symptoms by using principal components and varimax rotation. The first factor comprised high scores on general somatic symptoms and accounted for $18 \%$ of the variances. The other three factors had an eigenvalue of more than one and explained fairly equally a further $32 \%$ of the variance; they highlighted psychological symptoms, vasomotor symptoms and aging symptoms.

\section{Influences on menopausal symptoms}

Each group of symptoms that emerged from the factor analysis was examined to see to what extent women reporting these problems differed from others in their current menopausal stage, self-rated health or social environment. Table 4 shows the results of a logistic regression model; hot flushes and night sweats represent vasomotor symptoms, anxiety and weakness represent general somatic symptoms, early waking represents psychological symptoms, and numbness represents aging symptoms.

In the logistic regression model considering the confounding factors on vasomotor symptoms, such as age, self-rated health, life satisfaction, social support, occupation and behavior, the perimenopausal and postmenopausal women remained strongly associated with vasomotor symptoms, with greater odds ratios than the premenopausal groups (Table 4). Postmenopausal women stiil showed an increase in risk over the premenopausal women for hot flushes and night sweats, having adjusted odds ratios of 2.06 (95\% CI: 1.37-3.09) for hot flushes and 1.84 (95\% CI: 1.26-2.67) for night sweats. The association between farm occupation and vasomotor symptoms was strengthened after adjustment for other factors, showing half the odds compared with all other occupations. The women engaged in agriculture had a larger number of family members than the women in other occupations $(4.58 \pm 1.41$ and $3.73 \pm 1.51$, respectively; $P<0.001$ ), but there were no significant differences in lifestyle, social support, self-rated health, life satisfaction or age by occupation. Having no close friends (odds ratio of 1.62, 95\% CI: 1.11-2.38) was an indicator of increased risk for hot flushes. Self-rated health and life satisfaction did not retain an independent association with vasomotor symptoms. 

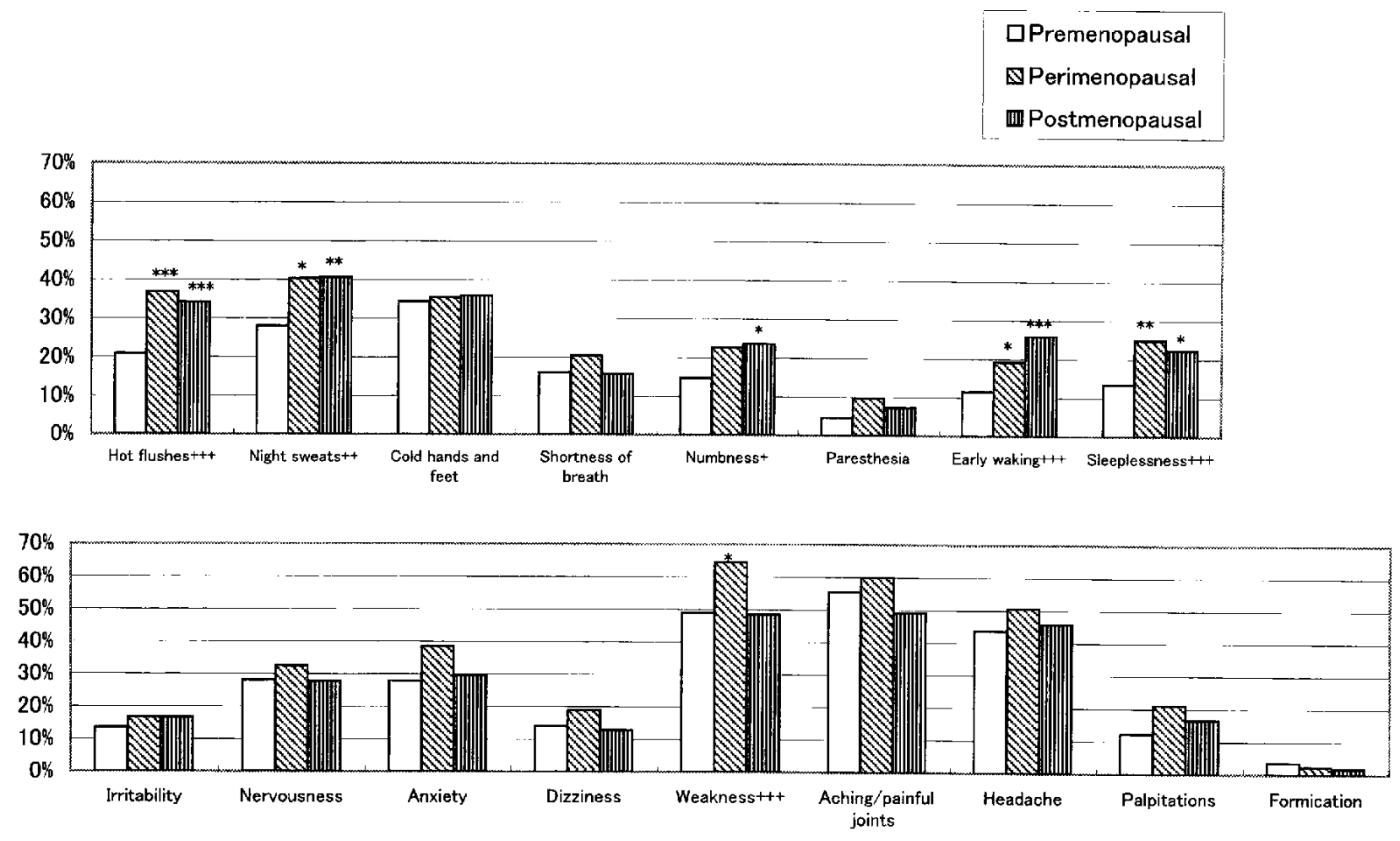

Fig. 1. Freqency of menopausal symptoms in women aged 45 to $54 \mathrm{yr}$ by menopausal stage. $P$ values for the symptoms were expressed as +: $P<0.05,++: P<0.01$ and $+++P<0.001$ by using general $\chi^{2}$-test for three independence samples. $P$ values of the bar were expressed as *: $P<0.025, * *: P<0.005$ and $* * *: P<0.0005$ compared with premenopausal women by using $\chi^{2}$-test. The critical alpha value of post hoc analysis was set up by using Bonferroni's inequality and was divided by two on the two comparisons.

Table 3. Factor analysis of symptom groups in women aged 45 and $54 \mathrm{yr}$

\begin{tabular}{|c|c|c|c|c|}
\hline & $\begin{array}{c}\text { Factor 1: } \\
\text { General somatic } \\
\text { symptoms }\end{array}$ & $\begin{array}{c}\text { Factor 2: } \\
\text { Psychological } \\
\text { symptoms }\end{array}$ & $\begin{array}{l}\text { Factor } 3: \\
\text { Vasomotor } \\
\text { symptoms }\end{array}$ & $\begin{array}{l}\text { Factor 4: } \\
\text { Aging } \\
\text { symptoms }\end{array}$ \\
\hline Weakness & 0.64 & 0.19 & 0.09 & 0.14 \\
\hline Aching/painful joints & 0.58 & 0.04 & -0.02 & 0.10 \\
\hline Headache & 0.56 & 0.05 & 0.34 & 0.17 \\
\hline Anxiety & 0.55 & 0.48 & 0.09 & 0.17 \\
\hline Dizziness & 0.55 & 0.21 & 0.13 & -0.06 \\
\hline Palpitation & 0.54 & 0.04 & 0.19 & 0.38 \\
\hline Shortness of breath & 0.52 & 0.02 & 0.23 & 0.42 \\
\hline Cold hands and feet & 0.47 & 0.20 & 0.20 & 0.09 \\
\hline Sleeplessness & 0.09 & 0.84 & 0.22 & 0.09 \\
\hline Early waking & 0.09 & 0.81 & 0.23 & 0.02 \\
\hline Nervousness & 0.51 & 0.58 & -0.05 & 0.20 \\
\hline Irritability & 0.38 & 0.52 & 0.07 & 0.33 \\
\hline Night sweats & 0.02 & 0.21 & 0.76 & 0.14 \\
\hline Hot flushes & 0.24 & 0.10 & 0.74 & 0.11 \\
\hline Formication & -0.11 & 0.02 & 0.07 & 0.77 \\
\hline Numbness & 0.21 & 0.17 & 0.27 & 0.45 \\
\hline Paresthesia & 0.24 & 0.09 & 0.24 & 0.42 \\
\hline Eigenvalue & 3.0 & 2.4 & 1.6 & 1.6 \\
\hline$\%$ variance & 17.8 & 14.2 & 9.6 & 9.3 \\
\hline
\end{tabular}

Kaser-Meyer-Olkin measure of sampling adequacy $=0.868$. 
Table 4. Effect of variables on presence of vasomotor or other symptoms from a logistic regression analysis in women aged 45 to 54

\begin{tabular}{|c|c|c|c|c|c|c|}
\hline Variable & $\begin{array}{l}\text { Hot flushes } \\
\text { Odds ratio }\end{array}$ & $95 \% \mathrm{CI}$ & $\begin{array}{l}\text { Night sweats } \\
\text { Odds ratio }\end{array}$ & $95 \% \mathrm{CI}$ & $\begin{array}{l}\text { Anxiety } \\
\text { Odds ratio }\end{array}$ & $95 \% \mathrm{CI}$ \\
\hline \multicolumn{7}{|l|}{ Menopausal status } \\
\hline Premenopausal & 1.00 & & 1.00 & & 1.00 & \\
\hline Perimenopausal & 2.06 & $1.31-3.22$ & 1.52 & $1.00-2.32$ & 1.56 & $1.01-2.40$ \\
\hline Postmenopausal & 2.06 & $1.37-3.09$ & 1.84 & $1.26-2.67$ & 1.14 & $0.77-1.70$ \\
\hline \multicolumn{7}{|l|}{ Health } \\
\hline Self-rated health (Good/excellent) & 1.00 & & 1.00 & & 1.00 & \\
\hline Self-rated health (Average/bad/very bad) & 1.40 & $0.89-2.21$ & 1.30 & $0.86-1.98$ & 2.05 & $1.28-3.30$ \\
\hline Life satisfaction (Good/excellent) & 1.00 & & 1.00 & & 1.00 & \\
\hline Life dissatisfaction (Average/bad/very bad) & 0.86 & $0.56-1.34$ & 0.83 & $0.55-1.23$ & 1.43 & $0.91-2.24$ \\
\hline \multicolumn{7}{|l|}{ Social support } \\
\hline Close friends (Yes) & 1.00 & & 1.00 & & 1.00 & \\
\hline Close friends (No) & 1.62 & $1.11-2.38$ & 1.11 & $0.77-1.60$ & 0.86 & $0.59-1.26$ \\
\hline Social role (Yes) & 1.00 & & 1.00 & & 1.00 & \\
\hline Social role (No) & 0.83 & $0.58-1.18$ & 0.90 & $0.65-1.25$ & 1.46 & $1.03-2.07$ \\
\hline \multicolumn{7}{|l|}{ Occupation } \\
\hline Caring of eldely (No) & 1.00 & & 1.00 & & 1.00 & \\
\hline Caring of eldely (Yes) & 1.43 & $0.89-2.32$ & 1.23 & $0.78-1.96$ & 0.80 & $0.48-1.33$ \\
\hline Other occupations & 1.00 & & 1.00 & & 1.00 & \\
\hline Farmer & 0.52 & $0.31-0.87$ & 0.59 & $0.37-0.94$ & 0.72 & $0.45-1.16$ \\
\hline \multicolumn{7}{|l|}{ Behavior } \\
\hline Smoking (No) & 1.00 & & 1.00 & & 1.00 & \\
\hline Smoking (Yes) & 1.49 & $0.76-2.93$ & 1.26 & $0.65-2.45$ & 0.66 & $0.32-1.39$ \\
\hline Lifestyle score $>=7$ & 1.00 & & 1.00 & & 1.00 & \\
\hline Lifestyle score $<7$ & 1.02 & $0.71-1.48$ & 0.93 & $0.66-1.32$ & 1.45 & $1.01-2.09$ \\
\hline
\end{tabular}

\begin{tabular}{|c|c|c|c|c|c|c|}
\hline Variable & $\begin{array}{l}\text { Weakness } \\
\text { Odds ratio }\end{array}$ & $95 \% \mathrm{CI}$ & $\begin{array}{l}\text { Early waking } \\
\text { Odds ratio }\end{array}$ & $95 \% \mathrm{CI}$ & $\begin{array}{l}\text { Numbness } \\
\text { Odds ratio }\end{array}$ & $95 \% \mathrm{CI}$ \\
\hline \multicolumn{7}{|l|}{ Menopausal status } \\
\hline Premenopausal & 1.00 & & 1.00 & & 1.00 & \\
\hline Perimenopausal & 1.78 & $1.16-2.72$ & 1.56 & $1.01-2.40$ & 1.80 & $1.10-2.97$ \\
\hline Postmenopausal & 0.96 & $0.67-1.39$ & 1.14 & $0.77-1.70$ & 1.74 & $1.11-2.74$ \\
\hline \multicolumn{7}{|l|}{ Health } \\
\hline Self-rated health Good/excellent & 1.00 & & 1.00 & & 1.00 & \\
\hline Self-rated health Average/bad/very bad & 3.30 & $2.18-5.00$ & 2.05 & $1.28-3.30$ & 1.30 & $0.78-2.17$ \\
\hline Life satisfaction Good/excellent & 1.00 & & 1.00 & & 1.00 & \\
\hline Life dissatisfaction Average/bad/very bad & 0.92 & $0.61-1.38$ & 1.43 & $0.91-2.24$ & 1.00 & $0.61-1.62$ \\
\hline \multicolumn{7}{|l|}{ Social support } \\
\hline Close friends Yes & 1.00 & & 1.00 & & 1.00 & \\
\hline Close friends No & 0.68 & $0.48-0.98$ & 0.86 & $0.59-1.26$ & 1.32 & $0.86-2.01$ \\
\hline Social role Yes & 1.00 & & 1.00 & & 1.00 & \\
\hline Social role No & 0.83 & $0.60-1.15$ & 1.46 & $1.03-2.07$ & 0.73 & $0.49-1.09$ \\
\hline \multicolumn{7}{|l|}{ Occupation } \\
\hline Caring of eldely No & 1.00 & & 1.00 & & 1.00 & \\
\hline Caring of eldely Yes & 0.84 & $0.52-1.33$ & 0.80 & $0.48-1.33$ & 1.07 & $0.62-1.85$ \\
\hline Other occupations & 1.00 & & 1.00 & & 1.00 & \\
\hline Farmer & 0.65 & $0.42-0.99$ & 0.72 & $0.45-1.16$ & 1.08 & $0.65-1.79$ \\
\hline \multicolumn{7}{|l|}{ Behavior } \\
\hline Smoking No & 1.00 & & 1.00 & & 1.00 & \\
\hline Smoking Yes & 1.10 & $0.55-2.19$ & 0.66 & $0.32-1.40$ & 0.55 & $0.22-1.37$ \\
\hline Lifestyle score $>=7$ & 1.00 & & 1.00 & & 1.00 & \\
\hline Lifestyle score $<7$ & 1.45 & $1.03-2.03$ & 1.45 & $1.01-2.09$ & 1.29 & $0.86-1.94$ \\
\hline
\end{tabular}

A logistic regression was used to test for differences between the menopausal symptoms reporting groups adjusted for age, menopausal status, self-rated health, life satisfaction, social support, occupation and behavioral variables. CI: confidence interval. 
Frequency of anxiety and weakness as general somatic symptoms increased in the perimenopausal group, compared with the premenopausal and postmenopausal women: $39 \%, 28 \%$ and $30 \%$ for anxiety, and $64 \%, 49 \%$ and $49 \%$ for weakness, respectively. Perimenopausal women were bothered more by general somatic symptoms, except for cold hands and feet, than were their premenopausal and postmenopausal peers. General somatic symptoms in the perimenopausal stage showed odds ratios of $1.56(95 \% \mathrm{CI}: 1.01-2.40)$ for anxiety and 1.78 (95\% CI: 1.16-2.72) for weakness, compared with the premenopausal stage (Table 4). The postmenopausal stage did not retain an independent association with general somatic symptoms. Women with lower self-rated health produced higher odds ratios of 2.05 (95\% CI: 1.28 3.30 ) for anxiety and 3.30 (95\% CI: 2.18-5.00) for weakness, compared to the women with higher self-rated health. The relationship between a worse lifestyle and general somatic symptoms was strengthened after adjustment for other factors, and showed an odds ratio of 1.5 compared to a better lifestyle.

Postmenopausal and perimenopausal women were bothered more by early waking as a psychological symptom than were their premenopausal peers $(26 \%, 19 \%$ and $12 \%$, respectively; Fig. 1). Taking into account selfrated health, social support and lifestyle modified these relations, but compared with their premenopausal peers, perimenopausal women still showed an increase in risk with an adjusted odds ratio of 1.56 (95\% CI: $1.01-2.40)$; the postmenopausal group showed the same level of risk as the premenopausal women (odds ratio of $1.14,95 \%$ Cl: $0.77-1.70$ ). The association between poorer self-rated health and early waking was strengthened after adjustment for other factors, and showed a 2.05 in odds (95\% CI: $1.28-3.30)$ compared with better self-rated health. No social role (odds ratio of $1.46,95 \%$ CI: $1.03-$ 2.07 ) and worse lifestyle (odds ratio of $1.45,95 \% \mathrm{CI}$ : $1.01-2.09)$ were indicators of increased risk for early waking (Table 4).

Postmenopausal and perimenopausal women were bothered more by numbness as an aging symptom than were their premenopausal peers $(24 \%, 23 \%$ and $15 \%$, respectively; Fig. 1). Postmenopausal and perimenopausal women still showed an increase in risk for this symptom over premenopausal women, with an adjusted odds ratio of $1.74(95 \% \mathrm{Cl}: 1.1 \mathrm{I}-2.74)$ for postmenopausal and 1.80 (95\% CI: $1.10-2.97$ ) for perimenopausal women. The other factors did not retain an independent association with numbness (Table 4).

\section{Discussion}

\section{Vasomotor symptoms}

The present investigation confirms prior findings in Japan as well as studies in Europe and North America, as does the separate loading of vasomotor symptoms in the factor analysis ${ }^{20,21}$. Vasomotor symptoms - hot flushes and night sweats - were affected significantly by less regularity of the menstrual cycle in the present study. In the logistic regression model considering the confounding factors in vasomotor symptoms, the perimenopausal and postmenopausal stages remained strongly associated with vasomotor symptoms, with greater odds ratios than the premenopausal stage. The finding of a clear association with menopause and vasomotor symptoms concurs with many investigations in USA and Europe ${ }^{2,22}$. WHO also concluded that vasomotor symptoms and vaginal dryness were the only symptoms convincingly related to menopausal hormonal changes ${ }^{23}$.

In the present study, vasomotor symptoms, especially hot flushes, were eased by a farming occupation, and strengthened by having no close friends. Recent studies have indicated that personal factors such as social support, lifestyle and personality may affect the psychosocial stressors ${ }^{24,25)}$. It is believed that farming as an occupation is related to a large family, free time and freedom in daily life, with a resulting higher resistance to vasomotor symptoms.

\section{Other symptoms excepting vasomotor symptoms}

Reports of being bothered by other menopausal symptoms (excluding aging symptoms) increased significantly in the perimenopausal women, compared with the premenopausal and postmenopausal stages, in the logistic regression model. Other menopausal complaints excepting vasomotor symptoms are not considered typical of the climacteric as they also occur in non-climacteric persons, so that there is no evidence of a relationship to the climacteric hormonal changes ${ }^{18}$.

In the present study, the other menopausal symptoms (excepting aging symptoms) showed a strong association with self-rated health. Self-rated health is based on selfperceived, overall healthiness and measures both the objective information people have about their health status and their evaluation of the information ${ }^{12}$. Although subjective well-being can be influenced by personality factors and is not suitable for evaluating changes in the quality of life over time, it should correlate closely with objective indices and have discriminate validity ${ }^{26)}$. Perimenopausal women felt that they made little contribution to their family and community and felt weaker social support in the present study. Social support can be seen as a moderator of stress and fundamental to life $^{23)}$. The present investigation suggests that these other menopausal symptoms in the climacteric are more influenced by social circumstances than are the vasomotor symptoms.

\section{Characteristics in Japanese women}

In our study, one-third of the women in the climacteric suffered from vasomotor symptoms over a period of one 
yr, but their symptoms were not serious. In other studies in $\mathrm{Canada}^{43}$, the Netherlands ${ }^{22)}$ and the U.K ${ }^{27,28)}$, more than half of the perimenopausal women experienced such symptoms. The rate of hot flushes over the one yr period of the present study was in the mid-range of the rates reported for rural Japanese women and for Canadian women complaining of hot flushes over a two week period in 1983-1984 ${ }^{4}$. Although the frequency of hot flushes in the present study is believed to have increased as a result of rapid lifestyle change in the past ten yr in Japan and/or by the longer duration of menopausal symptoms compared with Lock's report ${ }^{4}$, the present results agree with the finding of a lower prevalence of hot flushes in Japanese women in comparison with Canadian women ${ }^{4}$.

Although the actual mechanisms of vasomotor phenomena have yet to be explained, high FSH levels and lower estradiol levels relate to the aetiology of hot flushes ${ }^{27}$. Investigations revealed the differences in sex hormone secretions in different ethnic populations of women including Japanese ${ }^{29}$, 30, but such differences do not appear to explain a significantly lower frequency of vasomotor symptoms.

Japanese women also have distinctive characteristics in the utilization of medical treatment for menopausal symptoms. In the present study, only $4.6 \%$ of rural Japanese women visited gynaecologists, who are the only physicians to prescribe HRT in rural communities for treatment of menopausal symptoms. The reported usage rate of HRT was 4\% of Japanese women in 1983-19844); $2.5 \%$ of urban women aged $45-64$ yr were current users of HRT and $6.3 \%$ of the same group were past users in $1992^{8}$. Significant predisposing factors for the personal use of HRT by women doctors in the U.K. were reported to be the presence and severity of menopausal symptoms, surgical menopause, past use of hormonal contraception and a family history of osteoporosis ${ }^{(0)}$. Low utilization of HRT by Japanese women seems to be related to the prohibition of oral hormonal contraception, but these findings could be explained by cultural differences with respect to lifestyle, belief and attitudes towards menopause and the aging process ${ }^{4}$.

Disturbances in the climacteric have been attributed to profound physical and psychosocial changes in women $^{3)}$. They are not simply manifestations of hormone deficiency ${ }^{8)}$. Initially prescribed for the treatment of vasomotor symptoms, HRT is now recommended for preventing osteoporosis, cardiovascular disease ${ }^{31 \text {, }}$, menopausal depression and Alzheimer's disease ${ }^{32)}$, and it might offer an additional bonus of increased well-being for healthy middle-aged women. Some physicians believing menopause to be caused by a biological deficiency of estrogens have tended to routinely treat all recently menopausal women with $\mathrm{HRT}^{31 !}$. Recent investigations indicate that self-esteem, coping and social support $^{14}$ ease the menopausal syndrome. Considering the low prevalence of vasomotor symptoms in Japan and the easing effects of social support and occupation in the present study, these alternative pathways could be useful in easing the menopausal syndrome in conjunction with HRT.

\section{Further investigations}

There are several limitations to the present study. The representative sample of women with a relatively high rate of recovery from the general population of various parts of Japan in the present study has the advantage of minimising the potential for a selection bias. As we had no information on non-responders in six communities, a selection bias could have occurred when women with menopausal symptoms responded to an invitation to participate in the present investigation. The overall recovery rate was relatively high, but two communities, Usuda and Toyono, had a lower response rate in the present survey. Nonetheless, the present study is the largest survey which has covered various parts of Japan so far.

As the menopausal samples included women with hysterectomies who had more complaints than normal climacteric women of the same age ${ }^{16)}$, the severity of menopausal symptoms in the menopausal women may be overestimated. Further, although we have no information on the rate of HRT and physician prescription patterns in our present study, the relationship between menopausal symptoms and the various menopausal stages was constant with or without the factor of women visiting gynaecologists. Women who had hysterectomies or used HRT reported frequencies of vasomotor symptoms similar to those of the perimenopausal women ${ }^{27}$. Considering the low rate of usage of HRT in Japan, it is assumed that there is little effect on menopausal symptoms by HRT intervention in the present population.

Many psychosocial factors ${ }^{33)}$ and lifestyle ${ }^{341}$ were found to be predictors of mood disorders during the climacteric. Further studies of menopausal symptoms should incorporate factors, together with biological investigations, factors such as past mood disorders, chronic illness, life events, socio-economic status, occupation, and most importantly the attitude toward menopause and aging.

This study was supported by the Development of Health Promotion Program in Middle-aged and Elder Women of Rural Communities from the Ministry of Health and Welfare of Japan in 1996-1997.

\section{References}

1) Kupperman HS, Wiesboden H, Blatt MHG. Contemporary therapy of the menopausal syndrome. JAMA 1959; 171: 1627-1637.

2) Bungay GT, Vessey MP, McPherson CK. Study of 
symptoms in middle life with special reference to the menopause. BMJ 1980; 281: 181-183.

3) Greene JG, Cooke DJ. Life stress and symptoms at the climacterium. Br J Psychiatry 1980; 136: 486-491.

4) Ballinger CB. Psychiatric aspects of the menopause. Br J Psychiatry 1990; 156: 773-787.

5) Richters JMA. Menopause in different cultures. J Psychosom Obster Gynecol 1997; 18; 73-80.

6) Beyenne Y. Cultural significance and physical manifestation of menopause, a biocultural analysis. Cult Med Soc 1986; 10: 47-71.

7) Lock M. Menopause in cultural context. Exp Gerontol 1994; 29: 307-317.

8) Lock M. Contested meanings of the menopause. Lancet 1991; 337: 1270-1272.

9) Salamone LM, Pressman AR, Seeley DG, Cauley JA. Estrogen replacement therapy: a survey of older women's attitudes. Arch Intern Med 1996; 156: 1293 1297.

10) Isaacs AJ, Britton AR, McPherson K. Why do women doctors in the UK take hormone replacement therapy? J Epidemiol Community Health 1997; 51: 373-377.

11) Nagata C, Matsushita Y, Shimizu H. Prevalence of hormone replacement therapy and user's characteristics: community survey in Japan. Maturitas 1996; 25: 201-207.

12) Waters WE, Heikkinen E, Dontas AS. Health, lifestyles and services for the elderly. Public Health in Europe 29, WHO Regional Office for Europe, Copenhagen, 1992.

13) Cooper CL, Roden J, Mental health and satisfaction among tax officers. Soc Sci Med 1985; 21: 747-751.

14) Ell K. Social networks, social support and coping with serious illness: the family connection. Soc Sci Med 1996; 42: 173-183.

15) Abe T, Yamaya $Y$, Suzuki M, Moritsuka T. Statistical clustering of women complaining of climacteric symptoms by cluster analysis. Acta Obst Gynaec Jpn 1979; 31: 607-614 (in Japanese).

16) Oldenhave A, Jaszmann LJB, Haspels AA. Hysterectomized women with ovarian conservation report more severe climacteric complaints than do normal climacteric women of similar age. Am J Obstet Gynecol 1993; 168; 765-771.

17) Kono S, Sunagawa $Y$, Higa $H$, Sunagawa $H$. Age of menopause in Japanese women: trends and recent changes. Maturitas 1990; 12: 43-49.

18) Whelan EA, Sandler DP, McConnaughey DR, Weinberg CR. Menstrual and reproductive characteristics and age at natural menopause. Am J
Epidemiol 1990; 131: 625-632.

19) Pett MA. Nonparametric statistics for health care research. Sage Publications, Thousand Oaks, 1997.

20) Greene JG. A factor analytic study of climacteric symptoms. J Psychosom Res 1976; 40: 425-430.

21) Holte A, Mikkelsen A. The menopausal syndrome: a factor analytic replication. Maturitas 1991; 13: 193203.

22) Oldenhave A, Jaszmann LJB, Haspels AA, Everaerd WTAM. Impact of climacteric on well-being. Am J Obstet Gynecol 1993; 168: 772-780.

23) World Health Organization. Research on the menopause. Report of a WHO scientific group. Technical Report Series 670, WHO, Geneva, 1981.

24) Lin N, Dean A. Social support and depression: A panel study. Soc Pshchiatry 1984; 19: 83-91.

25) Rabkin JG, Streuning EL. Life events, stress, and illness. Science 1976; 194: 1013-1020.

26) Muldon MF, Barger SD, Flory JD, Manuck SB. What are quality of life measurements measuring? BMJ 1998; 316: $542-545$.

27) Guthrie JR, Dennerstein L, Hopper JL, Burger HG Hot flushes, menstrual status, and hormone levels in a population-based sample of midlife women. Br J Obstet Gynecol 1996; 103: 1025-1028

28) Kuh LD, Wadsworth M, Hardy R. Women's health in midlife: the influence of the menopause, social factors and health in earlier life. $\mathrm{Br}$ J Obstet Gynaecol 1997 ; 104: 923-933.

29) Hill P, Wynder EL, Helman P, Hickman R, Rona G, Kuno K. Plasma hormone levels in different ethnic populations of women. Cancer Res 1976; 36: 22972301 .

30) Shimizu H, Ross RK, Bernstein L, Pike MC, Henderson BE. Serum oestrogen levels in postmenopausal women: comparison of American whites and Japanese in Japan. Br J Cancer 1990; 62: 451-453.

31) Rosenberg L. Hormone replacement therapy: the need for reconsideration. Am J Public Health. 1993; 83, 1670-1673.

32) Tang MX, Jacobs D, Stern Y, et al. Effects of oestrogen during menopause on risk and age at onset of Alzheimer's disease. Lancet 1996; 348; 429-432.

33) Hunter MS. Depression and the menopause. BMJ 1996; 313: 1217-1218

34) Nagata C, Shimizu H, Takami R, Hayashi M, Takeda N, Yasuda K. Hot flushes and other menopausal symptoms in relation to soy product intake in Japanese women. Climacteric 1999; 2: 6-12. 